\title{
Impact of Ethics and Social Awareness Curriculum on the Engineering Identity Formation of High School Girls
}

\author{
Gabriel Burks ${ }^{1}\left(\mathbb{D}\right.$, Kathryn B.H. Clancy ${ }^{2}$, Carla D. Hunter ${ }^{3}$ and Jennifer R. Amos ${ }^{1, * \mathbb{D}}$ \\ 1 Department of Bioengineering, University of Illinois at Urbana-Champaign, Urbana, IL 61801, USA; \\ gabrielb@illinois.edu \\ 2 Department of Anthropology, University of Illinois at Urbana-Champaign, Champaign, IL 61820, USA; \\ kclancy@illinois.edu \\ 3 Department of Psychology, University of Illinois at Urbana-Champaign, Urbana, IL 61801, USA; \\ chunter1@illinois.edu \\ * Correspondence: jamos@illinois.edu
}

Received: 2 August 2019; Accepted: 26 September 2019; Published: 28 September 2019

\begin{abstract}
A national need exists to effectively engage women and people categorized as minorities in science, technology, engineering, and mathematics (STEM) fields and career paths. Given the minimal existence of standards and accreditation boards for engineering design and holistic engineering practice in $\mathrm{K}-12$ contexts, we must better understand how said engineering design and holistic engineering practice affects the learning and identity formation of K-12 students. Here, 50 rising 9th-12th grade girls are exposed to either a socio-ethics enhanced engineering curriculum or a standard engineering curriculum through a week-long STEM summer camp. Qualitative methods are used to conduct a thematic analysis on the engineering language used by students in each curriculum group. Significant differences in language and attitudes towards engineering and the practice of STEM subjects is observed through the incorporation of ethics and humanities into a standard model engineering curriculum. The study presented in this paper demonstrates that students have a tendency towards describing scientific ideas through abstract terms, while a group who participated in the social science integrated camp tended to describe scientific ideas using social-emotional terms. Lastly, students who participated in the camp with integrated social sciences displayed an expanded view and sense of responsibility for the society for which their science is developed to serve. These results could have implications on how STEM subjects are communicated to attract and sustain student interest.
\end{abstract}

Keywords: holistic engineering; identity formation; K-12; STEM; ethics; thematic analysis; diversity; women in STEM

\section{Introduction}

The United States has been largely ineffective in sufficiently engaging diverse populations, including women and people categorized as ethnic or racial minorities, in science, technology, engineering, and mathematics (STEM) fields and career paths [1-4]. This shortcoming has resulted in a shortage in internationally competitive STEM talent and an insufficiently trained domestic workforce incapable of continuing past successes [5]. To combat this, there has been a heavily focused domestic initiative to engage diverse populations and previously untapped underserved minority groups-particularly female participation in STEM. To begin framing this large issue, two general explanations are put forth for women's underrepresentation in science: (1) Either women act differently from men (the difference model), or (2) they are treated differently in the culture of science (the 
structural deficit model) [6]. According to the difference model, the causes of gender disparities in career achievement are held to lie within women themselves. The gender differences are said to be innate or else to be the result of gender-role socialization or cultural patterns [7]. With regards to the structural deficit model (not deficits associated with women themselves), women as a group receive fewer chances and opportunities in their careers, and for this reason they collectively have worse career outcomes. In this model, the emphasis is on structural obstacles—legal, political, and social—that exist (or existed earlier) within the social system of science [8].

To engage previously untapped human capital, there has been a corresponding shift in pedagogical diversity, curriculum diversity, faculty/staff diversity, and an influx of monetary resources in spaces of learning [9-17]. Pedagogical strategies including active learning, project-based learning, and team-based learning all generally aim to increase engagement in students to support the development of their persistence in STEM subjects. More and more institutions of learning are recognizing the importance of fielding a diverse faculty offering to best serve their continually diversifying student population [18-20].

Secondary to such innovations in education is understanding the parallel impact of said innovations on the persistence, perceptions, and STEM identity formation of the targeted diverse populations. This is not to imply that pedagogy or education structural factors are the only impactors of persistence in STEM fields because this issue is very nuanced and there are many impactors [6]. Several social and systemic structures contribute to the complex identity formation of future STEM professionals. The formation of STEM communities, presence of relatable STEM mentors, self-efficacy, development of teamwork and leadership skills, and having meaningful research experiences all contribute to the persistence and identity formation of future STEM professionals [21-24].

In many instances, even with substantial innovations in the STEM educational offerings, said offerings continue to restrict the open participation of all students. Unfortunately, STEM in its purest form still carries a stigma regarding who may participate and how one must be pre-molded to fit into a historical culture of STEM. One such example of historical culture in STEM is gender representation across STEM disciplines, where the women who choose to pursue pathways in STEM disproportionately choose life science-based majors over physical science, math, and computer science majors (Figure 1) [25]. Data from Figure 1 is also particularly interesting because it represents STEM PhD holders in academia and in terms of a rite of passage, academia is unequivocally the primary space where rite of passage is granted and communal perceptions are developed for the next generation of STEM leaders. In essence, issues of access, inclusion, equity, recruitment, and retention in academic institutions provide a direct lens into what should be expected in the future workforce, albeit in industry or academia. As recently as 2010, women only represented 20 percent of the full-time faculty population in Engineering, Math, and Physical Science fields; whereas in the life sciences they represented roughly 42 percent of the population. The three examples chosen in Figure 1 paint very unique pictures of gender representation across STEM disciplines: (A) classic STEM fields in math and physical sciences that have historically been dominated by males, (B) the life sciences that have been uncharacteristically welcoming to women in STEM, and (C) the growth of an emerging STEM discipline where gender representation was essentially zero for both groups at its inception. This data begets the question, why did the engineering, math, physical sciences, and computer sciences areas not experience comparable female participation to that of the life sciences? 

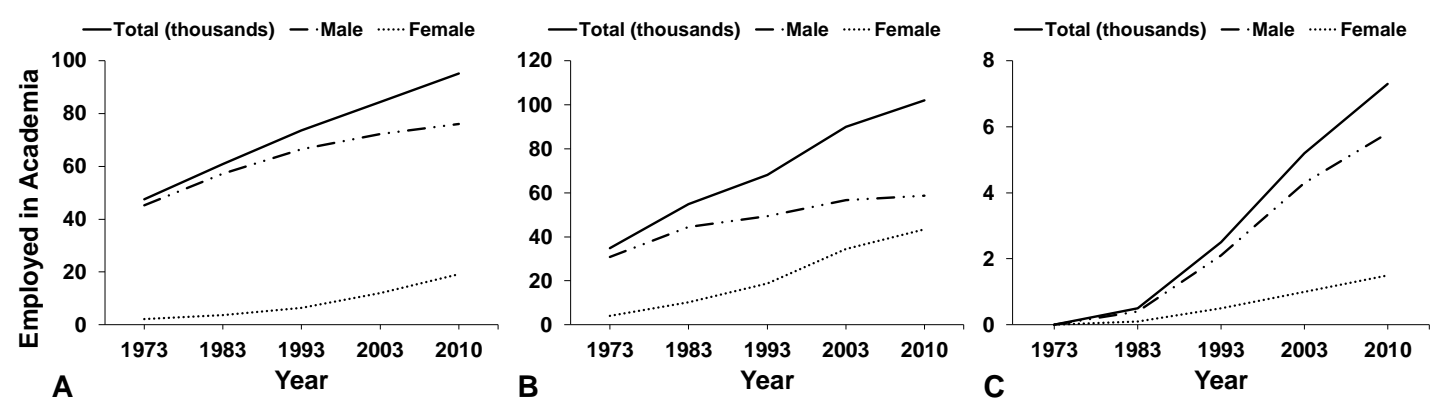

Figure 1. Science, technology, engineering, and mathematics (STEM) PhD Holders in Academia by Gender, from 1973-2010. (A) Engineering, Math, and Physical Sciences, (B) Life Sciences, and (C) Computer Sciences. Source: Data from the National Academies of Sciences, Engineering, and Medicine Statistic Tables.

To approach explanations to this question, some have investigated differences in male-female natural aptitude for science [26-28], personal preference [29,30], self-perception [31,32], structure and environment of academic science [33-35], and gender segregation differences among academic scientists [25]. To that point, it has been found that men and women have very few differences in their natural aptitude for science. Another significant component in the pursuit of a particular STEM discipline is the presence or absence of same-sex role models. It has been found that if classes in a major are taught by women, then women are more likely to pursue that major regardless of discipline [36,37]; however, differences may exist in a graduate school context. Nonetheless, in such an environment where, statistically speaking, the presence of "like" role-models may be more difficult to come by, significant hurdles may exist subsequently discouraging women and minorities from entering into these STEM spaces or forcing them out once they do enter. It must also be said that in male-dominated environments, it has been shown that women are more likely to switch out of STEM majors in response to poor performance compared to men [38].

A particularly interesting assertion as to why women tend to migrate towards the life sciences involves the idea that innate differences exist between men and women which cause women to be better suited for and/or more interested in biology than the physical sciences. In a study comparing narratives of gender separation in science between mixed-gender communities of biologists and physicists in academia, women often used language that demonstrated a broader understanding of or emotional or societal attachment to the subject (meaning that women are better able to connect to the subject matter of biology, such as working with animals, versus the subject matter of physics, such as working with particles); whereas men often cited the abstract nature of physical sciences and specific mathematics abilities as drivers of their own interest [25]. Finally, in another study respondents stressed differences in discipline specific outcomes, perceiving that biologists are more likely to work on research that would have practical consequences. More specifically, a postdoctoral fellow in biology talked about the social benefits that her research might bring: "I think women ... want to have more of a sense that what they are doing is helping somebody.... Maybe there are more women in ... biology [because] you can be like 'Oh, I am going to go cure cancer.'” This respondent was intensely aware of the possible implications that her work might have on society, and this narrative was not common among the men studied in biology. This suggests that the perceived practical applications of biology are gendered, which may be a result of societal expectations that women are best suited to emotional labor, labor that involved one-on-one contact, helping another, particularly the production of an emotional state in another individual $[25,39]$. This assertion aligns favorably to the relatively recent integration of the arts into STEM practice.

A secondary strategy that has been implemented with success has been the incorporation of the "Arts" into STEM (STEAM). The merger of humanities and traditional STEM curricula enforces the idea that the $21^{\text {st }}$ century scientist and engineer must maintain a higher sense of responsibility 
for the societal outcomes that result from the introduction of new science and technology [40-42]. Such incorporation of the humanities may dually serve as a net for attracting demographics that have not traditionally identified with the pure STEM fields and, secondly, as a platform for the training of socially aware and accountable STEM professionals who subsequently have a responsibility to train the next generation of STEM talent. The intended long-term impact of this work is to enrich science education by encouraging incorporation of a more inclusive and holistic view of science. Educational programs intended to pique interest in STEM disciplines can be further enhanced while also providing a framework for discussion of current issues, such as healthcare, health disparities, and sustainability to be addressed in the tradition STEM context.

If indeed differences exist between men and women's interest in STEM as a function of their social-emotional connection to the subject matter, then reframing the traditional STEM narrative, traditionally devoid of humanities, into a narrative where STEM, the arts, and the humanities coexist harmoniously should be expected to come with more social-emotional connections conducive to gender-based persistence in STEM.

In this report, the aim is to show how the incorporation of ethics and social awareness into a standard summer engineering curriculum impacts the engineering identity formation of pre-college girls. This work will help to identify how and whether the intentional incorporation of ethics and social awareness into an engineering curriculum changes the engineering language and perceptions of engineering that pre-college girls have. Ideally, topics regarding the epistemological development of students would also be breached here; however, experimental limitations and timing have prevented that.

\section{Theoretical Framework}

To validate the relevance of ethics and awareness of social impacts resulting from produced science and technology, we draw on both The Framework for Quality K-12 Engineering Education (QEE) and the Socioscientific Issues (SSI) frameworks. The QEE framework was developed using a design-based research methodology, which is often domain dependent, and whereby it becomes crucial to outline any accompanying assumptions through its use [43-46]. Here the assumptions were gathered and addressed via multiple iterative cycles of revision to develop a refined and concise engineering education framework [47]. This particular framework is essential in that it addresses a gap between dedicated standards and pedagogical procedures for incorporation of engineering education in the $\mathrm{K}-12$ and undergraduate education contexts. Many of the pedagogical standards and procedures for engineering education at the undergraduate level are managed via respective engineering accreditation boards (i.e., Accreditation Board for Engineering and Technology (ABET), et al.); however, those same boards seldom exist for K-12 engineering education. Therefore, an important step towards the effective development of $\mathrm{K}-12$ engineering education best practices and instruments rest on the consequent development of a standard $\mathrm{K}-12$ engineering education framework.

Underneath the umbrella of The Framework for Quality K-12 Engineering Education lies 12 key indicators that, when taken together, summarize a quality engineering education for all students throughout their K-12 education experience [43] and encompass both aspects that are fundamental to effective engineering and aspects that are more cross-cutting in nature as it relates to the broadly defined disciplines of Science, Technology, Engineering, and Mathematics. Here it can be found that Issues, Solutions, and Impacts (ISI), Ethics, Teamwork, and Engineering Communication are introduced as core competencies for a quality engineering education. These particular key indicators speak to the idealized holistic goal of STEM education [42,48]; however, in this context, they fall short on emphasizing the barriers that prevent STEM education from undoing its bifurcated ideology.

At this point it is most appropriate to introduce the SSI framework whereby many of the aforementioned shortcoming of the QEE are addressed and further developed. The practice of science can be viewed as possessing both normative (e.g., data gathering, observation, predictions, scientific methods and processes) and non-normative (e.g., prescribing courses of action, choosing to create 
selected products, decisions about what ought to be done) components [49]. The obvious shortcoming in the QEE framework is its lack of acknowledgement of the social responsibility of an engineer to "prescribe courses of action," "selectively create products," and "making decisions about what ought to be done." The QEE framework acknowledges that engineers should be trained to be aware of the social impacts of their work, but are not necessarily held accountable for their actions in a social sphere.

In combination, these two frameworks demonstrate that there is an important space for ethics and social action along with social awareness in engineering education curricula. Secondly, they demonstrate that the viability of society hinges on the voluntary and altruistic expression of holistically trained engineers. Our findings rely on the acceptance of these two constructs in that it will be shown that such holistically trained engineers must be trained in accordance to the desired ethical outcomes and it may not be assumed that they will act with sensible ethics in a vacuum.

\section{Methods}

\subsection{Research Design}

This is a grounded theory study utilizing the constant comparative method that begins with the initial question: How might the introduction of social science in traditional STEM curriculum alter the dynamics of STEM identity formation and narratives used to describe STEM subjects in young women [50-52]? Here, observations are made and analyzed thematically, and camp participant survey responses are analyzed for insights into their perceptions and priorities in STEM social systems. Guidelines provided by Creswell were also consulted in developing the research design for this project [53]. The approach is a convergent parallel-mixed methods and the research questions that are being addressed are: (1) Can a short intervention of social science in engineering change campers STEM language and perceptions of engineering within a 1-week long camp? (2) What themes emerge during design discussions between two camps? (3) What social themes emerge that can be linked to camper interest, identity, and environmental priorities?

\subsection{Camps}

Girls' Adventures in Mathematics, Engineering, and Science (GAMES) Bioengineering Camp is an annual week long camp, designed to provide high school girls (rising 9th-12th graders) an opportunity to explore engineering and scientific fields through demonstrations, classroom presentations, hands-on activities, and contact with women in these technical fields. These camps are also staffed by all-female college student counselors who guide participants through their weekly activities and who are residence with them throughout the night in a dormitory setting. These counselors have STEM backgrounds and usually have the most contact hours with campers collectively.

There are many tracks of the GAMES Camp series and this study focused on comparing two camps with similar structures and differing themes, where the Aerospace GAMES Camp is most analogous to traditional physical science curricula and the Bioengineering GAMES Camp aligns most favorably to traditional life science curricula.

Aerospace GAMES Camp. The camp structure is project driven with students rotating through different stations and activities throughout the day. Lectures are used to introduce each area before the activity as well as guest lectures from speakers who work on research related to aerospace engineering. There are several projects throughout the camp that require the campers to use design skills but without a culminating project at the end of the week. Example activities include building a glider, rocket launches, using flight control simulator and a field trip to a flight school.

Bioengineering GAMES Camp. The camp structure is project driven, with students rotating through different stations and activities throughout the day. Lectures are used to introduce each area before the activity. The camp also has daily active-learning lectures and short activities led by social scientists that engage the girls in discussions of a social and psychological nature and set the framework for the day. Throughout the day, the campers perform scientific experiments and design projects related to 
the topic of the day. The camp also features a more in-depth culminating project to link together the themes and projects done during the week. Example activities include 3D printing, building electronic sight sensors, biomimetics exploration, and a field trip to a medical simulation center.

\subsection{Participant Demographics}

Participants included 52 adolescent girls between the ages of 12 and 18. Informed consent was obtained from both the caregivers of and the individual participants included in the study. All participants completed a demographic survey which included selecting one or more from the racial categories used by the U.S. Census Bureau: Asian, Black, White, or Other, as well as selecting Hispanic or non-Hispanic. Bioengineering GAMES camp has 26 consented participants with self-identified racial demographics of $\mathrm{n}=3$ White, $\mathrm{n}=5$ Asian, $\mathrm{n}=5$ Hispanic, $\mathrm{n}=4$ Black, $\mathrm{n}=9$ Other. Aerospace GAMES had 24 consented participants with self-identified racial demographics of $n=12$ White, $n=9$ Asian, $\mathrm{n}=2$ Hispanic, $\mathrm{n}=0$ Black, $\mathrm{n}=1$ Other.

\subsection{Research Methods \& Data Collection}

\subsubsection{Video Capture}

Qualitative analysis of the respective camps was conducted to better understand the themes that were expressed through the language used by camp participants. The standard and socio-ethics enhanced camps were video recorded at two points near their respective conclusion: a project planning session and the final project presentation. The video time points were consistent with the schedule for both camps and represents a period where the students would have been subjected to the entirety of the respective camp curriculum. Both camps instructed students to complete specific conceptual engineering challenges. Each challenge involved the use of the engineering design process and expected for students to conceptually design, model, and to make design considerations. Discussion topics during planning and presentation sessions about the designs or design considerations were completely up to the students.

\subsubsection{Student Video Thematic Analysis}

The discussions captured were transcribed manually by the research team. Transcriptions were checked by a second individual to ensure accurate transcription and to address difficult segments of the recording. The videos captured during the camp were then coded using emergent themes that reflected the discussion (for example, themes involving engineering language used, ethical considerations made, and general perceptions of engineering were investigated). Codes were then organized into broader themes. Themes were separated by the type of curriculum exposed to the student groups (e.g., Standard and Socio-ethics enhanced).

The research team then used the data analysis approach described by reference [54]. First, the team read all of the transcripts to familiarize themselves with the data as a whole. An open coding process was followed where codes were developed from the transcripts, followed by axial coding where the codes were analyzed to see if there was any connection between the codes. The codebook was developed based on the project research questions and the collected data. Codes were then organized into broader themes. As data was interpreted, meaning-making was initially organized by research questions-e.g., themes related to social engineering context.

A codebook consisting of two main code categories (design and social) was developed during first-cycle coding from survey and open-ended response. From the main codes, four sub-codes emerged from the Standard Summer Camp and six sub-codes emerged from the Socio-ethics enhanced Summer Camp. The analysis of data (video participant quotes) that was inserted under these themes is described later in this paper. All codes directly related to the research questions. 


\subsubsection{Pre- and Post-Survey}

All camp participants were administered a pre-camp and post-camp survey, through the university's college of engineering, that included questions pertaining to their perceptions of and interest in engineering and STEM career paths. A second component of the surveys asks questions regarding student's most and least favorite aspects of the camp, suggested improvements for the camp, and who (if applicable) made their camp experience most enjoyable. These were separated by question and analyzed to determine the explicit theme of each response.

These survey results were collected blindly to the camp coordinators through the college of engineering and the results were aggregated and dispersed to respective camp leaders later in the summer. Student responses are completely anonymous. Here, these survey responses are used to gather brief and concluding snapshots of any prevailing thoughts and experiences that may be relevant to student STEM identity formation.

\section{Results}

\subsection{Standard Curriculum Themes}

In the standard model engineering summer camp, student participants were tasked with designing a space device for astronauts. As a byproduct of the challenge, there were humanistic or ethical decisions that may have had to be made as well as engineering design efficiency considerations. When analyzing the themes arising from the standard model engineering summer camp, as seen in Figure 1, four primary themes emerged from camp participants: (1) Cost, (2) Design Efficiency, (3) User Safety, and (4) User Experience. Specific quotes from students corresponding to the respective theme are also available in Figure 2.

\begin{tabular}{|c|c|c|c|}
\hline \multicolumn{4}{|c|}{ Standard Summer Camp Codes with Illustrative Data Excerpts } \\
\hline $\begin{array}{c}\text { Cost } \\
(N=11)\end{array}$ & $\begin{array}{c}\text { Design Efficiency } \\
(\mathrm{N}=11)\end{array}$ & $\begin{array}{l}\text { User Safety } \\
(\mathrm{N}=1)\end{array}$ & $\begin{array}{c}\text { User Experience } \\
(\mathrm{N}=1)\end{array}$ \\
\hline $\begin{array}{l}\text { "For the stabilization } \\
\text { we chose spin } \\
\text { because we thought } \\
\text { it was the most cost } \\
\text { efficient and } \\
\text { weighed less as } \\
\text { well..." }\end{array}$ & $\begin{array}{l}\text { "We did the feed horn } \\
\text { because it weighed less } \\
\text { and was functional" }\end{array}$ & $\begin{array}{l}\text { "For communication we chose both laser } \\
\text { and antennae because we wanted good } \\
\text { communication" (students referenced a } \\
\text { previous moon landing incident and belief } \\
\text { that better communication would prevent } \\
\text { similar issues in the future)* }\end{array}$ & $\begin{array}{l}\text { "Transfer time was } \\
\text { intermediate } \\
\text { because we didn't } \\
\text { want our astronauts } \\
\text { spending } 7 \text { years } \\
\text { [in space] before } \\
\text { proceeding..." }\end{array}$ \\
\hline $\begin{array}{l}\text { "We did spin } \\
\text { [because] it was } \\
\text { cheaper and it } \\
\text { weighed the least" }\end{array}$ & $\begin{array}{l}\text { "[We chose this design } \\
\text { because it] saved us a } \\
\text { lot of mass [even } \\
\text { though the cost went up } \\
\text { a lot]" }\end{array}$ & & \\
\hline $\begin{array}{l}\text { "We picked three } \\
\text { axis because it } \\
\text { wasn't a high cost..." }\end{array}$ & $\begin{array}{l}\text { "We chose solar rays } \\
\text { for power because they } \\
\text { last a long period of } \\
\text { time and they were cost } \\
\text { efficient" }\end{array}$ & & \\
\hline $\begin{array}{l}\text { "We chose solar } \\
\text { rays because it } \\
\text { wasn't as high of a } \\
\text { cost..." }\end{array}$ & & & \\
\hline
\end{tabular}

Figure 2. Arising themes from standard model engineering summer camp. Primary emerging themes are: (1) Cost, (2) Design Efficiency, (3) User Safety, and (4) User Experience. Where N is equal to the number of total qualifying responses counted. Brackets indicate paraphrased student statements and * represents authors' note.

With respect to the four primary emerging themes, the most frequently occurring themes were cost and design efficiency of the space device. Many students echoed similar sentiments as, "[we chose 
' $x$ ' design because ... ] 'it was most cost efficient and weighed less.'" This type of language is typical and is to be expected from participants in an engineering camp where engineering competency and engineering design practice are at the forefront of camp objectives. As has previously been demonstrated, usage of engineering jargon and practicing the ability to solve an engineering problem are both clear indicators of developing science self-efficacy and positive engineering identity formation [21].

To the contrary, there were only two instances where students drew attention to the physical or ethical experiences of astronauts. Those two themes were user safety and user experience. When making critical determinations of the specific equipment to use for their space device design, one group cited that it was important for them to have strong communication between themselves and the astronauts (as to prevent a previously observed disaster that resulted from poor communication); while another group acknowledged that they would prefer to sacrifice engineering design efficiency to provide a shorter amount of time for their astronauts to be in space (citing the comfort and safety of the astronauts as the primary concern). An efficient engineering design may have provided a more durable or faster operating space device, but the previously mentioned students exercised their human empathy when making material determinations, even without being prompted to do so.

Beyond the two mentioned instances where empathy, ethics, and/or social accountability were exhibited, the standard model engineering camp produced a disproportionate amount of student responses that solely prioritize the engineering design process without giving consideration to the human experience. This is not to insinuate that the students in this study would not be sufficient in executing the given engineering task; however, it does bring into question the hidden curriculum and culture that may be unintentionally emphasized in STEM programs $[55,56]$ where there may be a tendency to solve a specific problem at all costs and with minimal regard to human or ethical consideration. Perhaps issues regarding human and ethical considerations come later in the design process, or perhaps such considerations are the responsibility of the user to express?

\subsection{Socio-Ethics Enhanced Curriculum Themes}

Thematic analysis of the socio-ethics enhanced engineering camp provided for a richer theme experience, which is demonstrated by the range and variety of themes that emerged in Figure 3. The challenge in the socio-ethics enhanced camp required students to develop conceptual engineering devices to track and investigate a robot-based population. Similar to the standard model engineering camp, the challenge gives the opportunity for students to solely focus on the science and feasibility of their device or to make other considerations regarding the ethics or humanity of their respective devices.

\begin{tabular}{|c|c|c|c|c|c|}
\hline \multicolumn{6}{|c|}{ Socio-Enhanced Summer Camp Codes with Illustrative Data Excerpts } \\
\hline $\begin{array}{l}\text { Human-Centered Design } \\
\qquad(\mathrm{N}=2)\end{array}$ & $\begin{array}{l}\text { Phenotypic Variance } \\
(\mathrm{N}=4)\end{array}$ & $\begin{array}{l}\text { Boundaries of Discrimination } \\
\qquad(\mathrm{N}=3)\end{array}$ & $\begin{array}{l}\text { User \& Environmental Safety } \\
\qquad(\mathrm{N}=3)\end{array}$ & $\begin{array}{l}\text { Technological Exclusivity } \\
\qquad(\mathrm{N}=3)\end{array}$ & $\begin{array}{l}\text { Boundaries of Privacy } \\
(\mathrm{N}=4)\end{array}$ \\
\hline $\begin{array}{l}\text { "The eyeglass projects } \\
\text { multicolored light controlled } \\
\text { by the button and a slider in } \\
\text { the shape of an iris..." }\end{array}$ & $\begin{array}{l}\text { "We also need } 3 \\
\text { different color LEDs so } \\
\text { that the glasses could } \\
\text { switch between the } \\
\text { different eye colors" }\end{array}$ & $\begin{array}{l}\text { "We also have adjustable } \\
\text { brightness sliders...since } \\
\text { different eye colors may need a } \\
\text { different frequency [of } \\
\text { brightness]..." }\end{array}$ & $\begin{array}{l}\text { "It does not directly harm the } \\
\text { user..." }\end{array}$ & $\begin{array}{l}\text { "It will not be sold to the } \\
\text { public..." }\end{array}$ & $\begin{array}{l}\text { "It does nothing to the } \\
\text { brain..." }\end{array}$ \\
\hline \multirow[t]{3}{*}{$\begin{array}{l}\text { "A possible example could } \\
\text { look like this...(students } \\
\text { show a real city map as an } \\
\text { example)*" }\end{array}$} & $\begin{array}{l}\text { "You can adjust what } \\
\text { percentage of the } \\
\text { color...to make other } \\
\text { eye colors as well..." }\end{array}$ & $\begin{array}{l}\text { "Our prompt was a pretty } \\
\text { negative bias towards } \\
\text { cyborgs..." }\end{array}$ & $\begin{array}{l}\text { "They could walkthrough and } \\
\text { experience different surgeries or } \\
\text { situations without putting } \\
\text { themselves or others in danger..." }\end{array}$ & $\begin{array}{l}\text { "You don't have to worry about } \\
\text { it somehow becoming a } \\
\text { problem in the public" }\end{array}$ & $\begin{array}{l}\text { "You are logging data from } \\
\text { people...invasion of privacy } \\
\text { vs their safety" }\end{array}$ \\
\hline & $\begin{array}{l}\text { "Detect cyborgs by } \mathrm{pH} \text {, } \\
\text { cell size, cell type..." }\end{array}$ & $\begin{array}{l}\text { "Discrimination against people } \\
\text { who cant afford this particular } \\
\text { product...cyborgs and people } \\
\text { with metal parts..." }\end{array}$ & $\begin{array}{l}\text { "The chemicals and the metals } \\
\text { inside the solar panel may have } \\
\text { toxic effects" }\end{array}$ & $\begin{array}{l}\text { "If the island were real then it } \\
\text { would be cut away from } \\
\text { anything else..." }\end{array}$ & $\begin{array}{l}\text { "Project involves both the } \\
\text { DNA and cells of the } \\
\text { subject..." }\end{array}$ \\
\hline & $\begin{array}{l}\text { "We would use a true } \\
\text { color patch to conform } \\
\text { to any skin color..." }\end{array}$ & & & & $\begin{array}{l}\text { "Technology] is invasive } \\
\text { because there is a camera } \\
\text { an it is on most of the } \\
\text { time..." }\end{array}$ \\
\hline
\end{tabular}

Figure 3. Emerging themes from Socio-ethics enhanced engineering summer camp. Themes that arose are: (1) Human-Centered Design, (2) Phenotypic Variance, (3) Boundaries of Discrimination, (4) User and Environmental Safety, (5). Technological Exclusivity, and (6) Boundaries of Privacy. Where N is equal to the number of total qualifying responses counted. Brackets indicate paraphrased student statements and * represents authors' note. 
The emerging themes for this camp were: (1) Human-Centered Design, (2) Phenotypic Variance, (3) Boundaries of Discrimination, (4) User and Environmental Safety, (5) Technological Exclusivity, and (6) Boundaries of Privacy. These themes all occurred regularly throughout the video analysis. In many ways, the themes expressed in the socio-ethics enhanced engineering camp took on an identity of getting the task done the right way without sacrificing the humanity/rights of all beings. Many of the quotes may also be co-coded for "design efficiency." Interestingly, unlike the standard camp model, these students never mentioned cost as an engineering design consideration or constraint. Maybe this indicates a student belief that any price may be paid when a lifeform is at stake.

Some fundamental questions that arose from the primary themes are things such as: (1) Who or what deserves ethical protections or considerations? (2) How far should technology go to accommodate human phenotypic variance? (3) What is privacy, who has a right to infringe, and under what circumstances? When placed into the context of practicing STEM in the field, these questions and considerations align favorably with the ideals expressed in the SSI framework; whereby, STEM practitioners should take a more responsible approach towards the science for which they create or are the gatekeepers for. Analysis of the student responses shows that the engineering design process does not have to be sacrificed in the presence of a socially-responsive curriculum.

\subsection{Student Identity \& Connections to Humanities Driven STEM Content}

Through analysis of responses collected via pre- and post-surveys, patterns pertaining to student STEM identity formation and structural affinity (are there particular structural aspects of the camp that participants are drawn to?) are identified. Narratives are categorized to fit into one of three stratifications: (1) Content specific (interest in the abstract), (2) Social-Emotional (interest in the tangible or simulated experiences), or (3) Neutral. These categories align with the stratifications presented in previous works regarding rationales for major selection of women [25]. A content specific, or interest in the abstract, response is one where the responder is primarily interested in the details of learning about a specific topical area. This interest could be for any STEM area; however, for this type of response no interest is explicitly expressed towards the social or emotional themes related to the topical area. This is not to imply that students who express content specific responses do not have any social or emotional interest, but rather highlights the order of priorities for said responder. A social-emotional, or interest in the tangible or simulated experiences, response is one where the responder is primary interested drawing a connection between a given content area and some social or emotional aspect. These social or emotional aspects could be anything from conducting activities with other people or developing relationships to foreshadowing future implications of pursing the particular content area long-term (e.g., will I be happy in this career path? How will I or my work impact the lives of others?). A neutral response is one that is ambiguous in nature and does not explicitly fit into either of the two former categories.

\subsubsection{Commonalities between Socio-Ethics Enhanced and Standard STEM Camps}

Common to both camps, the campers overwhelmingly expressed a strong affinity towards camp counselors. For example, in response to the question, "who made the camp experience awesome? Some typical responses were 'my counselors had a huge part in it. They all were great and friendly which made it easy and fun to hang around them (camp \#1)' ... ' my camp counselor and camp coordinator (also female) were very encouraging and helpful throughout. I felt I could have a conversation with both of them and they would be supportive (camp \#1) ... ' my counselor made GAMES awesome because she gave us many opportunities and chances to take on different experiences (camp \#1)' ... 'I liked all the counselors. I had a chance to talk personally to them and they were all super sweet and kind ... they were all super willing to help and I admire their passion for Aerospace. All these ladies gave great advice and I could tell they cared a lot about us over our time together (camp \#2)' ... 'my counselors were great ... they made things fun and light (camp \#2)' ... and 'The staff made me feel so welcomed and it felt that they wanted to get to know each person even though they knew they might 
never see them again after one week... They made no one feel left out (camp \#2).'" These responses may hint at affinities common to all young women who aspire to pursue subjects in STEM. Many of the narratives align favorably with key impactors of forming a STEM identity, especially things such as presence of like role-models and non-threating structural environments in non-male dominated spaces.

\subsubsection{Standard and Socio-Ethics Enhanced STEM Camp Narratives from Pre- and Post-Surveys}

In Tables 1 and 2, data is presented for Standard and Socio-Ethics Enhanced STEM Camp participants for the following questions: (1) what was your favorite lesson or project? Why? (2) Best thing about this GAMES Camp? Tables 1 and 2 show a breakdown of student responses from the standard and socio-ethics enhanced GAMES curricula, respectively, when separated by the theme of the response to fit into one of the three selected categories (Social-emotional, content specific, or neutral). $\mathrm{N}$ is the total number of campers who responded in each respective category (summation of a row would give the total number of camper responses) and the percent shown is the percentage of responses out of the total response pool who fall into the respective category.

For the standard STEM camp (Table 1), in response to question 1, more than twice the responses were content specific $(62.5 \%)$ in nature compared to social-emotional ones $(29.2 \%)$. For question 2, more campers had social-emotional (58\%) driven responses than content specific (38\%) responses. This shift in the response narrative should be expected since question 2 refers to camper experiences with regards to the entire camp which also has a significant social component. When the responses from questions 1 and 2 are combined, the results are nearly equally social-emotional driven (43.9\%) and content specific driven (50\%). Since question one allows students to only focus on content and their experiences within the content (if applicable to the individual), there is a potential to obtain $100 \%$ content specific responses but much lower potential to obtain a $100 \%$ social-emotional response rate. Question two allows for them to focus on either their social experiences or their specific content experiences, if applicable, meaning it is possible to obtain a 100\% response rate in either category if a student has a particular affinity to either aspect of the camp. When taken into account, it would be reasonable to see an even split between social-emotional and content specific responses when the questions are combined.

Table 1. Standard STEM Camp Responses to Questions about their Camp Experiences

\begin{tabular}{cccc}
\hline \multicolumn{4}{c}{ Response Categories for Standard GAMES Camp in Aerospace Engineering } \\
\hline \multirow{2}{*}{ What was your favorite } & Social-Emotional & Content Specific & Neutral \\
\cline { 2 - 4 } & $\mathrm{N}=7$ & $\mathrm{~N}=15$ & $\mathrm{~N}=2$ \\
& $29.2 \%$ & $62.5 \%$ & $8.3 \%$ \\
Best thing about this & Social-Emotional & Content Specific & Neutral \\
GAMES Camp? & $\mathrm{N}=14.5$ & $\mathrm{~N}=9.5$ & $\mathrm{~N}=1$ \\
& $58 \%$ & $38 \%$ & $4 \%$ \\
& Social-Emotional & Content Specific & Neutral \\
& $\mathrm{N}=21.5$ & $\mathrm{~N}=24.5$ & $\mathrm{~N}=3$ \\
& $43.9 \%$ & $50 \%$ & $6.1 \%$ \\
\hline
\end{tabular}

For the socio-ethics enhanced STEM camp (Table 2), in response to question 1, responses that were content specific (39.3\%) in nature compared to social-emotional (39.3\%) responses were evenly split. For question 2, the responses were overwhelmingly social-emotional $(96.4 \%)$ in nature with no responses that qualified as content specific $(0 \%)$. When the responses from questions 1 and 2 are combined, the results are skewed towards the social-emotional side $(67.9 \%)$ rather than the content specific side (19.6\%). This represents quite a shift from the standard camp and potential rationales will be discussed further below. 
Table 2. Socio-Ethics Enhanced STEM Camp Responses to Questions about their Camp Experiences.

\begin{tabular}{cccc}
\hline \multicolumn{4}{c}{ Response Categories for Socio-Enhanced GAMES Camp in Bioengineering } \\
\hline \multirow{2}{*}{ What was your favorite } & Social-Emotional & Content Specific & Neutral \\
\cline { 2 - 4 } & $\mathrm{N}=11$ & $\mathrm{~N}=11$ & $\mathrm{~N}=6$ \\
& $39.3 \%$ & $39.3 \%$ & $21.4 \%$ \\
Best thing about this & Social-Emotional & Content Specific & Neutral \\
GAMES Camp? & $\mathrm{N}=27$ & $\mathrm{~N}=0$ & $\mathrm{~N}=1$ \\
& $96.4 \%$ & - & $3.6 \%$ \\
& Social-Emotional & Content Specific & Neutral \\
& $\mathrm{N}=38$ & $\mathrm{~N}=11$ & $\mathrm{~N}=7$ \\
& $67.9 \%$ & $19.6 \%$ & $12.5 \%$ \\
\hline
\end{tabular}

To illustrate the predominating language used by campers to describe the "best" aspects of their camp experience, Figures 4 and 5 are word clouds constructed directly from the aggregated campers' responses to question 2 for the standard curriculum and socio-ethics enhanced curriculum camps, respectively. In these word clouds the size and darkness of the words correspond to their frequency of use within the text, with larger and darker text indicating higher frequency.

For the standard camp, the primary words used tended to be more content specific in nature (e.g., learn, aerospace, engineering, flying, building, etc.), but these words were also supported by many social-emotional words as well (e.g., love, campers, college, experience, etc.). In Figure 4, the word "learn" clearly sticks out from the rest and this is telling because it seems to speak to how oriented this group was towards content specific tasks. There is a clear desire to dive deeper into the presented content. This is supported by reviewing student survey comments. For example, several campers cited the desire to learn more about topics of interest, "I wish that we had gone more into the astronautics of the camp" ... "I wished I could learn about larger flights and their mechanics" ... and "I wish we learned more about aerodynamics of ships and submarines under water." This shows clear alignment between the primary cloud word, "learn" and its secondary and tertiary support words (i.e., flying, aerospace, and depth).

\section{aerospace amaing best better building camp campers campus career classes college cool depth different easy engineering exioged $e$ experience tavorite feel field right flying games getting gives going guest hands helpful interest job learn liked tove meet} observatory opportunity otherwise people pretty projects rocket seeing speakers things think understand week working

Figure 4. Narratives from Student Post-Survey Responses from the Standard Girls' Adventures in Mathematics, Engineering, and Science (GAMES) Camp with an Aerospace Engineering Theme.

For the socio-ethics enhanced camp, the primary words used tended to be more social-emotional in nature (e.g., friends, fun, experience, counselor, people, etc.) with very few content specific support words. In Figure 5, there is no singular primary word as in Figure 4; instead there is a primary cluster of words that include: friends, experience, counselor, and awesome. The overall composition 
of this word cloud included many more words indicating feelings and emotions towards the camp structure and other campers participating in the camp. These students' perceptions of this particular STEM environment seem to have been heavily dictated by environmental factors specific to their experience and they made a clear point to express those feelings and environmental factors in their camp reviews. For example, one camper cited the desire to have a deeper understanding of what it REALLY means to be a bioengineer, "I wanted to learn more about the day in the life of a bioengineer ... ".

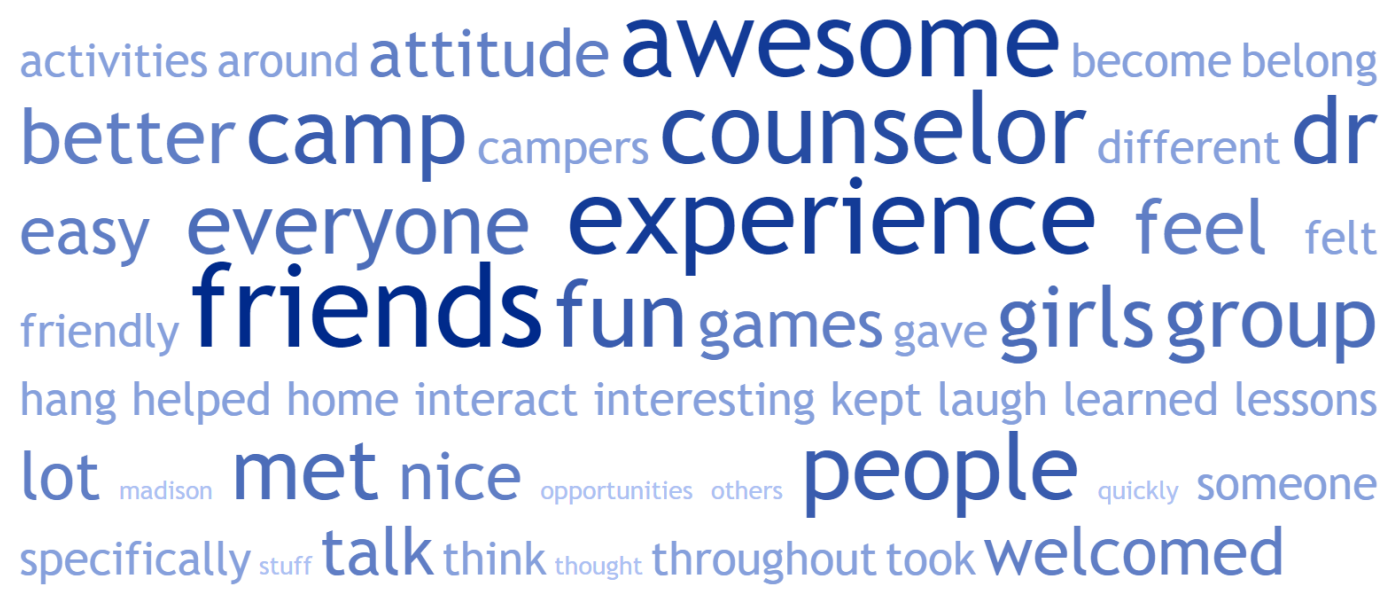

Figure 5. Narratives from Student Post-Survey Responses from the Socio-ethics enhanced GAMES Camp with the Bioengineering Theme.

\section{Discussion}

\subsection{Differences in Engineering Language across Camp Models}

The incorporation of ethics and humanities-based topics into standard engineering curriculum has a significant impact on how perceptions of engineering and STEM identities are formed. Without detailed information regarding the epistemological beliefs of camp participants, it can be seen that the language used across camp models is very different and distinct to specific realms of academic space. When viewed through the lens of the Socioscientific Issues framework, the differences in emerging themes really showcase the bifurcated ideology of science. The differences in themes and language used are excellent examples of the normative (e.g., prescribing courses of action, choosing to create selected products, decisions about what ought to be done) and non-normative (e.g., data gathering, observation, predictions, scientific methods and processes) components of practicing science [49]. For students from the standard model engineering camp, the language echoes the traditional engineering design process and the scientific method. These students were given an engineering task and they utilized their skills and scientific literacy to produce viable solutions. With respect to the SSI framework, we are forced to ask ourselves, is that enough? This is not to say that the students are at fault, but in many ways they are being taught by historical models of science that lean heavily towards objective arguments and inquiry with a solution in mind.

In many ways, the students who participated in the socio-ethics enhanced camp model deviated from the historical expectation of what STEM is and what the appropriate culture for STEM should be. Traditional barriers and design constraints are treated as afterthoughts, as shown in their emerging themes. Humane considerations are placed at the forefront of decision making and many of those same decisions are criticized and critiqued by their ethical nature. At its core, this new engineering design process is obviously more human-centered and socially cognizant. 


\subsection{Student Perceptions of the Role of Engineers}

Given the small student sample set, collecting substantial number of responses to establish meaningful significance would be a challenge; however, in our view of the perceptions of engineering between the two camp models, some emerging trends may exist. Though philosophically interesting, more thorough and robust investigation of the initial observations are necessary. With respect to the data, it was observed that in the case of students who experienced the socio-ethics enhanced curriculum, they tended to have perceptions of engineering that were counter to those perceptions of students who experienced the standard curriculum model. An example of one such engineering perception statement would be, "engineers do work that allows them to help their community and solve world problems." Socio-ethics enhanced students, in many cases experienced a net negative change between pre- and post-surveys on their affirmation of the previously mentioned statement; while standard curriculum students experienced a net positive change, where more students affirmed the statement in post-survey data. In general, we surely expect engineers to execute their roles with the highest levels of integrity and intention of good; however, when viewed through a more open-minded lens, it may be interpreted that as human beings, we all have a choice and even when our original intentions may be positive, sometimes the outcomes of our engineering innovations may not always remain within that same positive alignment. For example, nuclear power developed with good intention can help to alleviate a national power crisis and lessen the overall cost of energy for homes and consumers; however, that same nuclear technology was fundamental in the creation of the atomic bomb which has been used to devastate entire countries. Surely, the group of scientists who developed nuclear technology did not do so with the intention to kill hundreds of thousands of people. Higher awareness of the nature of man, spurred by the introduction of humanities-based narratives, may lend to this type of duality in thought and conscientious decision making. In the case where students were not exposed to such a curriculum, surely they too are operating with the most ethical of intentions and the practice of considering other societal possibilities was only neglected in oversight. To better reconcile such a stark difference in responses, and potentially in ideology, it may be simpler to refer to the SSI framework for clarity. Zeidler states, "We need to ask ourselves if we can imagine a world where one can be properly identified as being scientifically literate, yet bear no responsibility to subsequent decisions made about policy, research, community, family, and the like. We would likely agree that such an individual would possess technical competence, but lack the inclination to enact that knowledge with due consideration of the physical or social environment [49]." In other words, it may be possible that students exposed to the socio-ethics enhanced model camp are experiencing a byproduct of practicing the humanities; the acceptance of the subjective nature of the world around us contrary to the objective nature of STEM. Could their responses speak to their understanding that engineers may or may not do the things labeled in the survey because they recognize that all humans have the right to choose their own identity?

\subsection{Student Identity and Connections to Humanities Driven STEM Content}

A key component in the introduction of humanities into STEM curriculum is supposedly the added social-emotional connection to traditionally abstract science subjects as a means to increase female student STEM interest and persistence. Drawing parallels to work on why women potentially migrate toward the life sciences, where women often use language that demonstrates a broader understanding of or emotional or societal attachment to the subject whereas men often cite the abstract nature of physical sciences and specific mathematics abilities as drivers of their own interest, would lead us to believe that these themes should be present in the narratives of students who shared their experiences and perceptions of the summer camp. Through analysis of student experiences and perception of the GAMES summer camp, we see differences in the priorities of interests and ways in which students from each camp choose to describe those experiences. When speaking about their favorite aspects of the lessons and projects they experienced during the camp (Tables 1 and 2), majority of standard GAMES camp participants really spoke to their enjoyment of the content presented. Meanwhile, socio-ethics 
enhanced GAMES camp participants were split evenly on citing their enjoyment of the content and the social-emotional aspects of the content. A more interesting dynamic is how these groups chose to describe their overall favorite aspects of the camp experience. The examples of question 1 from Tables 1 and 2 are relatively one-sided in what they are asking for (specifically favorite aspects of content and lessons), therefore one would expect higher responses that are content specific in nature; conversely, question 2 is open-ended and there is an equal possibility that students could respond in terms of the content or social-emotional experiences. The actual time breakdown for the camps' week of activities is roughly $54 \%$ of time spent on content specific activities and roughly $46 \%$ of time spent doing social activities. In both camp models, the majority of the campers describe their favorite aspects of the entire camp experience in terms of prioritizing their social-emotional experiences. Combined, roughly $78 \%$ of all campers (from both camps) expressed their favorite aspects in terms prioritizing their social-emotional experiences. Considering how much contact time is actually spent on either content specific activities or social activities, the fact that in the standard model camp ( $38 \%$ content specific, 58\% social-emotional) and the socio-ethics enhanced model camp ( $0 \%$ content specific, $96.4 \%$ social-emotional) the campers had responses much higher in the social-emotional domain than the time allocated for doing social-emotional activities in the camp is telling of how and in what types of critical moments these young women draw from the STEM activities that they partake in. Also interesting here is the bifurcation in how the young women from both groups seem to prioritize their camp objectives. From the word clouds in Figures 4 and 5, it is clear that learning specific content is the primary driver for participants in the standard model aerospace engineering camp, while socializing and developing meaningful relationships is the primary driver in the socio-ethics enhanced model bioengineering camp. We do not believe that either of these findings are a result of the differences in camp curriculum; instead, we believe that this opens the door for a different conversation. Instead of asserting that men and women are innately different, it may be more fitting to acknowledge that some men and women tend to prefer content specific or abstract STEM narratives, while others tend to connect to more social-emotional or tangible STEM narratives. Perhaps STEM disciplines have done a poor job historically of acknowledging anyone, albeit male or female, who tends to migrate towards interests in social-emotional or tangible themes in STEM. Is it imperative to hang on to these traditional STEM narratives for a productive and competitive STEM workforce? We would tend to lean towards the opposite, where we believe that it would only strengthen our STEM thought diversity and STEM productivity by providing more diverse narratives that speak equitably towards people who align with either type of STEM narrative.

\subsection{Secondary Impacts of Humanities-Enhanced STEM Curriculum}

Beyond the obvious benefit of lowering the energy barrier for minority access into STEM fields, the introduction of the humanities into STEM curriculum dually provokes conversations that are nontraditional to the STEM context. Since science professors not only transfer scientific knowledge to their students but also have a major impact on the how those students frame gender, minoritization, access, pursuit of higher education, and discipline choice, it cannot be understated that their own perceptions of what science is, is not, and what it can be inevitably shape the culture of science and the structures that in turn shape the science profession. Furthermore, the practice of STEM professors leading and facilitating humanities-based conversations will no doubt impact and potentially reshape their own intrinsic biases and perceptions of STEM, which could produce significant gains in the re-landscaping of STEM culture.

\section{Conclusions}

Recall that the purpose of this study was to show how the incorporation of ethics and social awareness into a standard summer engineering curriculum impacts the engineering identity formation of pre-college girls. Drawing on the Framework for Quality K-12 Engineering Education (QEE) and the Socioscientific Issues (SSI) framework to highlight the need for and role of ethics and humanities 
in STEM-based curriculums, and qualitative data, this important question is answered. Secondarily, these two frameworks provide a blueprint for how a synergy between STEM and the humanities may be put into tangible practice and for how we may expect shifts in student's perspectives through humanities incorporation. Results of this study suggest several key conclusions.

First, the incorporation of humanities into a traditional STEM curriculum will diversify the lens and viewpoints from which STEM is discussed, resulting in the subsequent introduction of more social and emotional connection points for young women who wish to pursue subjects in STEM. Recall how students who participated in the socio-ethics enhanced camp model described their science in terms atypical to traditional STEM culture (Figure 3) compared to students who participated in a standard model STEM camp (Figure 2). This finding aligns favorably with the practice of normative and non-normative science [49] and demonstrates that secondary humanities-based considerations must be practiced and learned before they can be unconsciously implemented in the field. In other words, students in this STEM context must be taught to consider social and ethical issues before they should be expected to implement those considerations on their own.

Second, social and emotional connection-points to subject content are critical to effectively engage young women in traditional STEM disciplines. Historical data shows that the life sciences have been particularly successful at recruiting the interests of women and the theories as to why that is the case are many; however, assertions that women tend to connect to and rationalize their STEM work differently than men [25] are affirmed here. As demonstrated in Tables 1 and 2 and Figures 4 and 5 , in both the standard and socio-ethics enhanced camp models, campers expressed their favorite camp experiences in both social-emotional and content specific terms; however, in the socio-ethics enhanced camp which is most like traditional life sciences there was an overwhelming citing of social and emotional experiences as most memorable to the camp week. As a follow-up to this, it would be interesting to see if young men also cite such social and emotional experiences in a similar camp setting, or not, and if these expressions of experiences age dependent.

Lastly, regardless of specific STEM discipline interest, an equitable science social system structure and ample opportunities for success are a necessity for young women interested in pursuing disciplines in STEM. Though differences existed regarding how both groups communicated their STEM interests (social-emotional vs content specific), strong commonalities existed in their affinity towards camp counselors and their necessary interactions with said counselors. Campers' statements affirm the importance of the presence of like role models and non-threatening structural environments for the productive formation of their STEM identity [21]. Counselors in this context were also female STEM majors who shared many social contact hours with campers throughout the camp week. These interactions between campers and counselors played a large role in shaping camper perceptions of the social structural environment and culture of practicing STEM.

Finally, this work sets the stage for some potential future research. Given that women connect to their STEM work differently than men and therefore would seem to be more drawn towards the introduced social-emotional connections into traditional STEM curriculum, it would be interesting to see how the interest in and perceptions of STEM for young men are impacted by the introduction of social and ethics curriculum. I posit that the earlier that humanities-based narratives are introduced into STEM, the greater impact it will have on the culture and structural systems of STEM, thus supporting the development of equitable science social systems. Another potential subject of interest could look at what specific science environmental structures minorities migrate towards under circumstances where they are socially welcomed and not. These things could all push our practice of STEM toward fostering a more equitable science culture. It is possible and arguably more human for a greater synergy to exist between STEM and the Humanities.

Author Contributions: Conceptualization, G.B. and J.A.; Data curation, G.B.; Formal analysis, G.B.; Funding acquisition, J.A.; Investigation, G.B.; Methodology, J.A.; Supervision, J.A.; Writing - original draft, G.B. and J.A.; Writing-review and editing, G.B. and J.A.

Funding: This research received no external funding. 
Acknowledgments: We would like to thank our collaborators, Carla D. Hunter and Kathryn B.H. Clancy both of the University of Illinois Urbana-Champaign, for their contributions to the social science curriculum elements of the camp and support of this work. This research is covered under University of Illinois IRB \#14864.

Conflicts of Interest: The authors declare no conflict of interest.

\section{References}

1. Beede, D.N.; Julian, T.A.; Khan, B.; Lehrman, R.; McKittrick, G.; Langdon, D.; Doms, M.E. Education supports racial and ethnic equality in STEM. Econ. Stat. Adm. Issue Brief 2011. [CrossRef]

2. Chubin, D.E.; May, G.S.; Babco, E.L. Diversifying the engineering workforce. J. Eng. Educ. 2005, 94, 73-86. [CrossRef]

3. National Science Board. The Science and Engineering Workforce: Realizing America's Potential; National Science Foundation: Alexandria, VA, USA, 2003.

4. Selby, C.C. Women in Science and Engineering; Academy of Sciences: New York, NY, USA, 1999.

5. Marginson, S.; Tytler, R.; Freeman, B.; Roberts, K. STEM: Country Comparisons: International Comparisons of Science, Technology, Engineering and Mathematics (STEM) Education. Final Report; Australian Council of Learned Academies: Melbourne, Australia, 2013.

6. Sonnert, G. Women in science and engineering: Advances, challenges, and solutions. Ann. N.Y. Acad. Sci. 1999, 869, 34-57. [CrossRef]

7. Fausto-Sterling, A. Myths of Gender: Biological Theories about Women and Men; Basic Books: New York, NY, USA, 2008.

8. Epstein, C.F. Deceptive Distinctions: Sex, Gender, and the Social Order; Yale University Press: New Haven, CT, USA, 1988.

9. Bonwell, C.C.; Eison, J.A. Active Learning: Creating Excitement in the Classroom. 1991 ASHE-ERIC Higher Education Reports; The George Washington University: Washington, DC, USA, 1991.

10. Prince, M. Does active learning work? A review of the research. J. Eng. Educ. 2004, 93, 223-231. [CrossRef]

11. Silberman, M. Active Learning: 101 Strategies To Teach. Any Subject; Prentice-Hall: Des Moines, IA, USA, 1996.

12. Barron, B.J.; Schwartz, D.L.; Vye, N.J.; Moore, A.; Petrosino, A.; Zech, L.; Bransford, J.D. Doing with understanding: Lessons from research on problem-and project-based learning. J. Learn. Sci. 1998, 7, 271-311.

13. Blumenfeld, P.C.; Soloway, E.; Marx, R.W.; Krajcik, J.S.; Guzdial, M.; Palincsar, A. Motivating project-based learning: Sustaining the doing, supporting the learning. Educ. Psychol. 1991, 26, 369-398.

14. Michaelsen, L.K.; Knight, A.B.; Fink, L.D. Team-Based Learning: A Transformative Use of Small Groups in College Teaching; Georgia Southern University: Statesboro, GA, USA, 2004.

15. Moog, R.S.; Spencer, J.N.; Straumanis, A.R. Process-oriented guided inquiry learning: POGIL and the POGIL project. Metrop. Univ. 2006, 17, 41-52.

16. Antonio, A.L. Diverse student bodies, diverse faculties. Academe 2003, 89, 14. [CrossRef]

17. Hurtado, S.; Milem, J.; Clayton-Pedersen, A.; Allen, W. Enacting Diverse Learning Environments: Improving the Climate for Racial/Ethnic Diversity in Higher Education. ASHE-ERIC Higher Education Report, Vol. 26, No. 8; ERIC Clearinghouse on Higher Education: Washington, DC, USA, 1999.

18. Glass, C.; Minnotte, K.L. Recruiting and hiring women in STEM fields. J. Divers. High. Educ. 2010, 3, 218. [CrossRef]

19. Blackwell, L.V.; Snyder, L.A.; Mavriplis, C. Diverse faculty in STEM fields: Attitudes, performance, and fair treatment. J. Divers. High. Educ. 2009, 2, 195. [CrossRef]

20. Smith, D.G.; Turner, C.S.; Osei-Kofi, N.; Richards, S. Interrupting the usual: Successful strategies for hiring diverse faculty. J. High. Educ. 2004, 75, 133-160. [CrossRef]

21. Chemers, M.M.; Zurbriggen, E.L.; Syed, M.; Goza, B.K.; Bearman, S. The role of efficacy and identity in science career commitment among underrepresented minority students. J. Soc. Issues 2011, 67, 469-491. [CrossRef]

22. Hunter, A.B.; Laursen, S.L.; Seymour, E. Becoming a scientist: The role of undergraduate research in students' cognitive, personal, and professional development. Sci. Educ. 2007, 91, 36-74. [CrossRef]

23. Litzler, E.; Samuelson, C.C.; Lorah, J.A. Breaking it down: Engineering student STEM confidence at the intersection of race/ethnicity and gender. Res. High. Educ. 2014, 55, 810-832. [CrossRef] 
24. Syed, M.; Zurbriggen, E.L.; Chemers, M.M.; Goza, B.K.; Bearman, S.; Crosby, F.J.; Shaw, J.M.; Hunter, L.; Morgan, E.M. The Role of Self-Efficacy and Identity in Mediating the Effects of STEM Support Experiences. Anal. Soc. Issues Public Policy 2018. [CrossRef]

25. Ecklund, E.H.; Lincoln, A.E.; Tansey, C. Gender segregation in elite academic science. Gend. Soc. 2012, 26, 693-717. [CrossRef]

26. Blau, F.D.; Brinton, M.C.; Grusky, D.B. (Eds.) The Declining Significance of Gender? Russell Sage Foundation: New York, NY, USA, 2006.

27. England, P.; Allison, P.; Li, S.; Mark, N.; Thompson, J.; Budig, M.J.; Sun, H. Why Are Some Academic Fields Tipping toward Female? The Sex Composition of US Fields of Doctoral Degree Receipt, 1971-2002. Sociol. Educ. 2007, 80, 23-42. [CrossRef]

28. McDonnell, F. Why so few choose physics: An. alternative explanation for the leaky pipeline. Am. J. Phys. 2005, 73, 583-586. [CrossRef]

29. Mason, M.A.; Ekman, E.M. Mothers on the Fast Track: How a New Generation can Balance Family and Careers; Oxford University Press: Oxford, UK, 2007.

30. Reskin, B. Sex. segregation in the workplace. Annu. Rev. Sociol. 1993, 19, 241-270. [CrossRef]

31. Steinpreis, R.E.; Anders, K.A.; Ritzke, D. The impact of gender on the review of the curricula vitae of job applicants and tenure candidates: A national empirical study. Sex Roles 1999, 41, 509-528. [CrossRef]

32. Correll, S.J. Gender and the career choice process: The role of biased self-assessments. Am. J. Sociol. 2001, 106, 1691-1730. [CrossRef]

33. Settles, I.H.; Cortina, L.M.; Malley, J.; Stewart, A.J. The climate for women in academic science: The good, the bad, and the changeable. Psychol. Women Q. 2006, 30, 47-58. [CrossRef]

34. Zuckerman, H.E.; Cole, J.R.; Bruer, J.T. The outer circle: Women in the scientific community. In This Volume is Based on Papers from Four Symposia Held at Stanford University, CA, from 1983 to 1986; WW Norton \& Co.: New York, NY, USA, 1991.

35. Fox, M.F. Women, science, and academia: Graduate education and careers. Gend. Soc. 2001, 15, 654-666. [CrossRef]

36. Bettinger, E.P.; Long, B.T. Do faculty serve as role models? The impact of instructor gender on female students. Am. Econ. Rev. 2005, 95, 152-157. [CrossRef]

37. Rask, K.N.; Bailey, E.M. Are faculty role models? Evidence from major choice in an undergraduate institution. J. Econ. Educ. 2002, 33, 99-124. [CrossRef]

38. Kugler, A.D.; Tinsley, C.H.; Ukhaneva, O. Choice of Majors: Are Women Really Different from Men? National Bureau of Economic Research: Cambridge, MA, USA, 2017.

39. Hochschild, A.R. The Managed Heart: Commercialization of Human Feeling; Univ of California Press: Berkeley, CA, USA, 2012.

40. Litzinger, T.; Lattuca, L.R.; Hadgraft, R.; Newstetter, W. Engineering education and the development of expertise. J. Eng. Educ. 2011, 100, 123-150. [CrossRef]

41. Bordogna, J.; Fromm, E.; Ernst, E.W. An integrative and holistic engineering education. J. Sci. Educ. Technol. 1995, 4, 191-198. [CrossRef]

42. Duderstadt, J.J. Engineering for a changing world. In Holistic Engineering Education; Springer: Berlin/Heidelberg, Germany, 2010; pp. 17-35.

43. Moore, T.J.; Glancy, A.W.; Tank, K.M.; Kersten, J.A.; Smith, K.A.; Stohlmann, M.S. A framework for quality K-12 engineering education: Research and development. J. Pre-Coll. Eng. Educ. Res. 2014, 4, 1-13. [CrossRef]

44. Cobb, P.; Confrey, J.; DiSessa, A.; Lehrer, R.; Schauble, L. Design experiments in educational research. Educ. Res. 2003, 32, 9-13. [CrossRef]

45. Edelson, D.C. Design research: What we learn when we engage in design. J. Learn. Sci. 2002, 11, $105-121$. [CrossRef]

46. Kelly, A.E.; Lesh, R.A.; Baek, J.Y. (Eds.) Handbook of Design Research Methods in Education: Innovations in Science, Technology, Engineering, and Mathematics Learning and Teaching; Routledge: Abingdon-on-Thames, UK, 2014.

47. Hjalmarson, M.A.; Lesh, R.A. Engineering and design research: Intersections for education research and design. In Handbook of Design Research Methods in Education: Innovations in Science, Technology, Engineering, and Mathematics Learning and Teaching; Routledge: Abingdon-on-Thames, UK, 2008; pp. 96-110. 
48. Sheppard, S.D. Taking Stock: A Look at Engineering Education at the End of the 20th Century and Beyond; American Society for Engineering Education: Washington, DC, USA, 2006.

49. Zeidler, D.L. STEM education: A deficit framework for the twenty first century? A sociocultural socioscientific response. Cult. Stud. Sci. Educ. 2016, 11, 11-26. [CrossRef]

50. Strauss, A.; Corbin, J. Grounded theory methodology. Handb. Qual. Res. 1994, 17, 273-285.

51. Glaser, B.; Strauss, A. The Discovery of Grounded Theory: Strategies for Qualitative Research; Chicago: Aldine, NJ, USA, 1967.

52. Corbin, J.M.; Strauss, A. Grounded theory research: Procedures, canons, and evaluative criteria. Qual. Sociol. 1990, 13, 3-21. [CrossRef]

53. Creswell, J.W.; Creswell, J.D. Research Design: Qualitative, Quantitative, and Mixed Methods Approaches; Sage Publications: Thousand Oaks, CA, USA, 2017.

54. DeCuir-Gunby, J.T.; Marshall, P.L.; McCulloch, A.W. Developing and using a codebook for the analysis of interview data: An example from a professional development research project. Field Methods 2011, 23, 136-155. [CrossRef]

55. Hacker, S.L. The culture of engineering: Woman, workplace and machine. Women's Stud. Int. Q. 1981, 4, 341-353. [CrossRef]

56. Vanderburg, W.H.; Khan, N. How well is engineering education incorporating societal issues? J. Eng. Educ. 1994, 83, 357-361. [CrossRef]

(C) 2019 by the authors. Licensee MDPI, Basel, Switzerland. This article is an open access article distributed under the terms and conditions of the Creative Commons Attribution (CC BY) license (http://creativecommons.org/licenses/by/4.0/). 